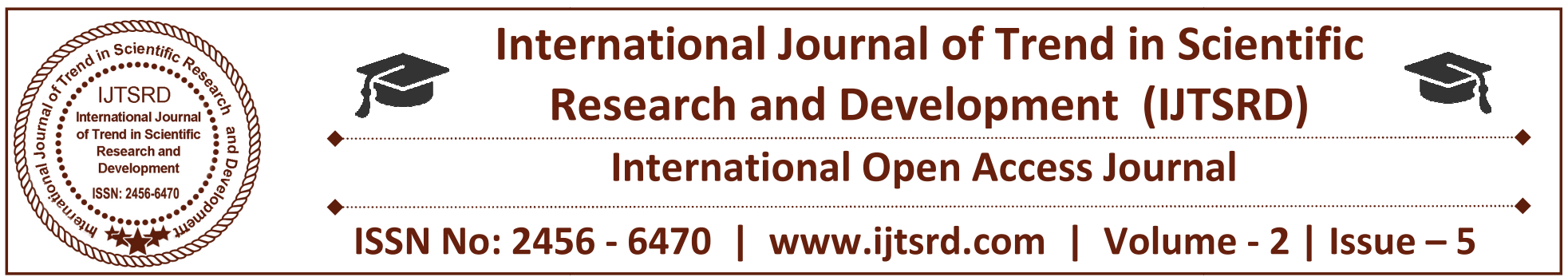

\title{
Study on the Properties of Self Cleaning Concrete Using Titanium Dioxide
}

\author{
Dr. S. U. Kannan', Jebin Raj ${ }^{2}$, Jerom Antony², Manoj ${ }^{2}$, Mujahid², \\ Professor $^{1}$, Final Year Students, \\ Department of Civil Engineering, Francis Xavier Engineering College, \\ Tamilnadu, India
}

\begin{abstract}
Concrete is the most widely used construction materials for building technology. However, cement production releases high amounts of carbon dioxide $(\mathrm{CO} 2)$ to the atmosphere that leads to increasing the global warming. The concrete materials also have been developed to be functioned as self-cleaning construction materials. The self-cleaning properties of the concrete are induced by introducing the photo catalytic materials such as titania ( $\mathrm{TiO} 2$ ) and zinc oxide $(\mathrm{Zn} \mathrm{O})$. Self-cleaning concrete that contains those photo catalysts will be energized by ultraviolet (UV) radiation and accelerates the decomposition of organic particulates. Thus, the cleanliness of the building surfaces can be maintained and the air surrounding air pollution can be reduced. In this paper a brief study has been carried out on the properties of self cleaning concrete using Titanium dioxide. The decolourization and oxidation effect are studied using Rhoda mine dye and nitrogen dioxide respectively.
\end{abstract}

Key Words: self cleaning, Titanium dioxide, Rhoda mine B Dye, Nitrogen Dioxide, Concrete

\section{INTRODUCTION}

A construction material removes pollutants from the air as it keeps its surface clean. This new astonishing concrete that not only keeps itself clean but also removes pollutants from the air is called Self Cleaning Concrete. The key to such properties are photo catalytic components that use the energy from ultraviolet rays to oxidize most organic and some inorganic compounds. Air pollutants that would normally result in discoloration of exposed surfaces are removed from the atmosphere by the components,
And their residues are washed off by rain. So, this new cement can be used to produce concrete and plaster products that save on maintenance costs while they ensure a cleaner environment. When light and heat strikes the concrete's surface, catalysts (usually titanium oxides) use that energy to break down the dirt into molecules like oxygen, water, carbon dioxide, nitrates, and sulphates. Gases float away, while liquids or solids are left on surface to be washed away by rain. Through a similar process, concrete can also break down pollutants in the air around it: if a pollutant strikes the surface, the titanium oxide reacts with it in the same way.

\section{Materials and their Properties \\ A. 6.4 Cement}

Cement is a material that has cohesive and adhesive properties in the presence of water. Such cements are called hydraulic cements. Cement is a binding material in concrete, which binds the other materials to form a compact mass. Generally OPC is used for all Engineering Construction works. OPC is available in three grades of 33, 43, and 53.In this project, 53 grade cement is used for the experimental study. Table 1 below shows the properties of cement.

Table1. Properties of Cement

\begin{tabular}{|l|l|l|}
\hline SI. No & Property & Value \\
\hline 1 & Specific Gravity & 3.15 \\
\hline 2 & Initial Setting time & $40 \mathrm{~min}$ \\
\hline 3 & Final Setting Time & $450 \mathrm{Min}$ \\
\hline 4 & Standard Consistency & $30 \%$ \\
\hline
\end{tabular}




\section{B. Fine Aggregate}

Concrete with better quality can be made with sand consisting of rounded grains rather than angular grains. River or manufactured sand must be used and not sea sand as it contains salt other impurities. In this project study, manufactured sand is used as fine aggregate. By conducting sieve analysis the zone is found.

Manufactured sand (M-Sand) is a substitute of river sand for concrete construction. Manufactured sand is produced from hard granite stone by crushing. The crushed sand is of cubical shape with grounded edges, washed and graded to as a construction material. The size of manufactured sand (M-Sand) is less than $4.75 \mathrm{~mm}$. Table 2 below shows the properties of river sand and M-sand

Table2. Properties of river sand and M-sand

\begin{tabular}{|l|l|l|l|}
\hline Sl. No & Properties & River Sand & M-Sand \\
\hline 1. & Specific Gravity & 2.62 & 2.84 \\
\hline 2 & Fineness modulus & 2.6 & 2.8 \\
\hline 3. & Water Absorption & $6.5 \%$ & $5.4 \%$ \\
\hline
\end{tabular}

\section{Coarse Aggregate}

Coarse aggregate is mined from rock quarries or dredged from river beds, therefore the size, shape, hardness, texture and many other properties can vary greatly based on location. Most generally, coarse aggregate can be characterized as either smooth or rounded (such as river gravel) or angular (such as crushed stone). Because of this variability, test methods exist to characterize the most relevant characteristics since exact identification would be impossible. Several key characteristics that are frequently used to describe the behaviour of coarse aggregates include relative density (or specific gravity), bulk density, and absorption. In our studies $20 \mathrm{~mm}$ aggregate is used. Table 3 shows the properties of coarse aggregates.

Table3. Properties of Coarse aggregate

\begin{tabular}{|c|c|c|}
\hline SI. No & Properties & Coarse aggregate \\
\hline 1. & Specific Gravity & 2.88 \\
\hline 2. & Impact Value & 26 \\
\hline 3. & Water Absorption & $0.5 \%$ \\
\hline
\end{tabular}

\section{Titanium Dioxide}

Titanium dioxide is a chemical compound, also known as titanium oxide or titania, is the naturally occurring oxide of titanium, chemical formula $\mathrm{TiO}_{2}$. The photo catalytic activity, which is another property of $\mathrm{TiO}_{2}$, is increased considerably through the high surface-to-volume ratio of the nano particles as compared to that of micro particles.

Scientific studies on photo catalysis started about two and a half decades ago. Titanium dioxide $\left(\mathrm{TiO}_{2}\right)$, which is one of the most basic materials in our daily life, has emerged as an excellent photo catalyst material for environmental purification. In this review, current progress in the area of $\mathrm{TiO}_{2}$ photo catalysis, mainly photo catalytic air purification is studied. Photo catalysis takes place only when the surface is treated with UV light or sun light. Its molecular formula $\mathrm{TiO}_{2}$ and molecular weight 79.87, is a kind of powder. Titanium dioxide colour is white. Formula for titanium dioxide is $\mathrm{TiO}_{2}$.

Titanium dioxide case no. IS 13463-67-7 is a soft solid and melts at 1800 Degrees Celsius. It has special performance, such as insulation, corrosion, flags, etc. It is polymorphous and it exists in three types of crystal structures a) rutile, b) anatase, c) brookite.

\section{Structure Of Titanium Dioxide:}

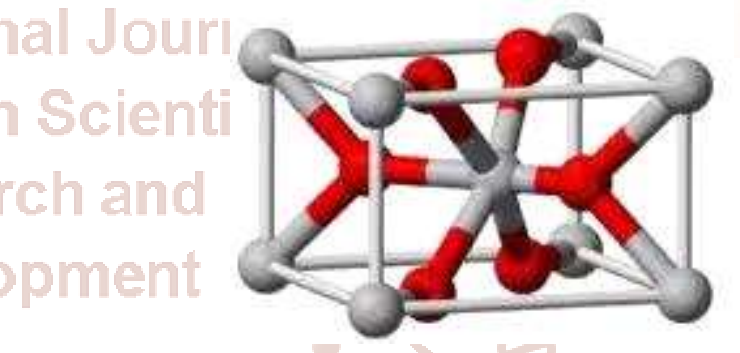

\section{Fig 1 Structure of Titanium Oxide}

\section{Physical structure:}

Rutile type, sharp titanium type; crystallization, department of the four winds of crystal,

\section{Lattice constant:}

A shaft $0.458, \mathrm{C}$ shaft 0.795 A shaft $0.378, \mathrm{C}$ shaft 0.949

A shaft: 7.19 X $10-62.88$ to $10-6$

C shaft: 9.94 X 10-6 6.44 to $10-6$

Almost everything has two aspects of the property. The titanium dioxide properties also have two sides: the physical properties of titanium dioxide and the titanium dioxide chemical properties. The physical properties of titanium dioxide include titanium dioxide solubility, titanium dioxide colour and so on. 
The Physical Property of Titanium Dioxide:

Molar mass

Refractive index

: $79.8658 \mathrm{~g} \cdot \mathrm{mol}-1$

Moh's Hardness

Capacitance ratio

$: 2.76 \sim 2.55$

: 6-7, 5.5-6

: 114 to 31

The coefficient of linear expansion: 25 ?

Thermal Conductivity

: 1.809 to 10.3

Oil Absorption

: $16 \sim 48,18 \sim 30$

Particle size

$: 0.2 \sim 0.3,0.3$

\section{Solubility:}

It is insoluble in dilute alkali, dilute acid, but soluble in hot concentrated sulphuric acid, hydrochloric acid, nitric acid. The solubility of titanium dioxide is related to solutes.

\section{Relative Density:}

In the commonly used white pigment, the relative density of titanium dioxide is mini mum. Of the same quality white pigment, titanium dioxide surface area is the largest and pigment volume is the highest.

\section{Permittivity:}

Because of high dielectric constant of titanium dioxide, it has excellent electrical properties. Anatase titanium dioxide's permittivity is lower, only 48.

\section{Conductivity:}

Titanium dioxide with the performance of the semiconductor, its conductivity increased rapidly with increasing temperature, but also is very sensitive to hypoxia.

\section{Melting and boiling points:}

It can be transformed into rutile when anatase and plate titanium dioxide are at high temperatures, so melting and boiling points of the board of rutile and anatase titanium dioxide actually does not exist. Only rutile titanium dioxide has a melting point and boiling point, rutile titanium dioxide, a melting point of 1850 $\mathrm{C}$, the melting point in oxygen-rich is $1879 \mathrm{C}$. The melting point of titanium dioxide is related to the purity of the titanium dioxide.

\section{Hydro scope city:}

Although titanium dioxide has hydro scope city, but not too strong, the hydrophilic is related to surface area, the surface area is larger; the moisture absorption is higher. The moisture absorption of titanium dioxide is relevant to the surface treatment and the nature too.

\section{Thermal Stability:}

Titanium dioxide has a good thermal stability, the general amount of $0.01 \%$ to $0.12 \%$.

\section{The Chemical Property of Titanium Dioxide:}

Titanium dioxide is non-toxic and chemical properties are stable. It almost has no reaction with other material produce under normal temperature. It is a partial acid. It has no reaction with oxygen, hydrogen sulphur, sulphur dioxide, carbon dioxide and ammonia and is not soluble in water, fatty acids, other organic acid and weak inorganic acid except for alkali and hot nitric acid.

But, in some specific conditions, titanium dioxide can get reaction with some substance. For example, these reactions as follows:

Only in the circumstance of long time boiling can it be totally soluble in strong sulphuric acid and hydrofluoric acid.

The reaction equation is as follows:

$\mathrm{TiO}_{2}+2 \mathrm{H}_{2} \mathrm{SO}_{4}=\mathrm{Ti}\left(\mathrm{SO}_{4}\right)_{4}+2 \mathrm{H}_{2} \mathrm{O}$

$\mathrm{TiO}_{2}+\mathrm{H}_{2} \mathrm{SO}_{4}=\mathrm{Ti} \mathrm{OSO}$

In this project cement is replaced by $3 \%, 4 \%$ and $5 \%$ of titanium dioxide and further examined.

\section{E. Rhoda mine B Dye}

It is a chemical compound and a dye. It is often used as a tracer dye within water to determine the rate and direction of flow and transport. dyes fluoresce and can thus be detected easily and inexpensively with instruments called. Rhoda mine dyes are used extensively in biotechnology applications such as fluorescence microscopy, flow cytometry, fluorescence correlation spectroscopy and ELISA.

\section{Properties}

Chemical formula: $\mathrm{C}_{28} \mathrm{H}_{31} \mathrm{C}_{1} \mathrm{~N}_{2} \mathrm{O}_{3}$

Molar mass: 479.02

Appearance: red to violet powder

Melting point: 210 to $211{ }^{\circ} \mathrm{C}$ (410 to $412{ }^{\circ} \mathrm{F} ; 483$ to $484 \mathrm{~K}$ )

Solubility in water: $\sim 15 \mathrm{~g} / \mathrm{L}\left(20^{\circ} \mathrm{C}\right)[1]$

\section{F. Nitrogen Dioxide}

Nitrogen dioxide is the chemical compound with the formula $\mathrm{NO}_{2}$. It is one of several nitrogen oxides. $\mathrm{NO}_{2}$ is an intermediate in the industrial synthesis of nitric acid, millions of tons of which are produced each 
year. At higher temperatures it is a reddish-brown gas that has a characteristic sharp, biting odour and is a paramagnetic, bent molecule with $\mathrm{C} 2 \mathrm{v}$ point group symmetry.

\section{Properties}

Chemical formula

Molar mass

Appearance

Odour

Density

Melting point

Boiling point

Solubility in water

Solubility

Vapour pressure

$: \mathrm{NO}_{2}$

: $46.0055 \mathrm{~g} \mathrm{~mol}-1$

: Vivid orange gas

Chlorine like

: $1.88 \mathrm{~g} \mathrm{dm}-3$ [2]

: $11.2^{\circ} \mathrm{C}\left(11.8^{\circ} \mathrm{F} ; 261.9 \mathrm{~K}\right)$

: $21.2^{\circ} \mathrm{C}\left(70.2^{\circ} \mathrm{F} ; 294.3 \mathrm{~K}\right)$

Hydrolyses

: soluble in $\mathrm{CCl} 4$, nitric acid.

Magnetic susceptibility $(\chi):+150.0 \cdot 10-6 \mathrm{~cm} 3 / \mathrm{mol}$

Refractive index $(\mathrm{N} \mathrm{d})$

Point group

Molecular shape

: $1.449\left(\right.$ at $\left.20^{\circ} \mathrm{C}\right)$

$: \mathrm{C} 2 \mathrm{v}$

Bent

Specific heat capacity (C) : $37.5 \mathrm{~J} / \mathrm{mol} \mathrm{K}$

Std molar entropy (So298: $240 \mathrm{~J}$ mol-1 K-1[4] STD enthalpy of formation $(\Delta \mathrm{fHo} 298) \mathrm{t}:+34 \mathrm{~K} j$ gel pores. mol-1 [4]

Main hazards

GHS signal word prominent air pollutant. Nitrogen dioxide is a

\section{Hazards}

$>$ Preparation of mould

$>$ Preparation of concrete

$>$ Preparing the specimen for testing.

Concrete was hand mixed and specimens were casted using steel moulds. Specimens were demoulded 24 hours after casting and cured at $272^{\circ} \mathrm{C}$ in water until the testing age of 28 days.

\section{Curing}

Concrete derives its strength by the hydration of cement particles. The hydration of cement is not a momentary action but a process continuing for long time. Of course, the rate of hydration is fast to start with, but continues over a very long time at a decreasing rate. The quantity of the product of hydration and consequently the amount of get formed depends upon the extent of hydration. It has been mentioned earlier that cement requires a w/e ratio about 0.23 for hydration and a w/e ration of 0.15 for filling the voids in a gel pores. In other works, a w/c of about 0.38 would be required to hydrate all the particles of cement and also to occupy the space in the

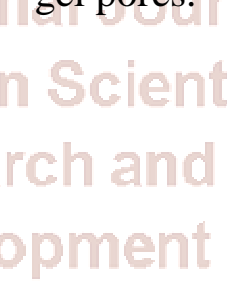

\section{Experimental Investigation}

\section{A. Batching of materials}

Volume batching is not good method for proportioning the material because of difficulty it offers to measure granular material in terms of volume. Volume of moist sand is loose conditions weighs much less than the same volume of dry compacted sand. The amount of solid granular material in cubic meter is indefinite quantities because of this for quality concrete materials have to measure by weigh only.

\section{B. Mixing and Casting}

The properties of the material, which are used for investigation, are presented in this section. All the experiments that are adapted to determine characteristics of the material are carried out as per Indian standards. This section also includes mix design for concrete as per Indian standards. The casting procedure was explained under five categories:

$>$ Material used

$>$ Mould details

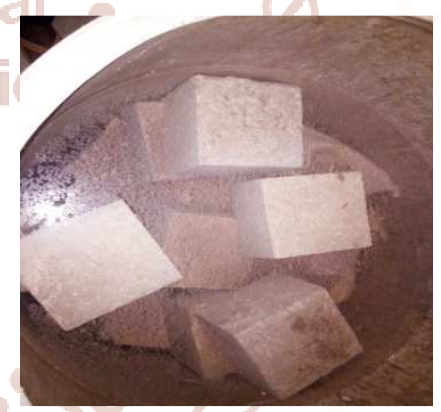

Fig 2 Curing Of Cubes
The experimental program was designed to study the properties of concrete with partial replacement of cement by titanium dioxide for M20 grade of concrete. The compressive strength of the cubes after replacing the cement by $3 \%$ and $4 \%$ and $5 \%$ as is check for after 28 days. For the test specimens, 53 grade ordinary Portland cement, manufactured sand and coarse aggregate, titanium dioxide are being utilized. The maximum size of the coarse aggregate was limited to $20 \mathrm{~mm}$. The concrete mix proportions of M20 with the water cement ratio of 0.4 were used.

The concrete mix design was proposed to achieve the compressive strength of $20 \mathrm{MPa}$ after 28 days curing, in case of cubes. The concrete cubes $(150 \mathrm{~mm} \mathrm{x}$ $150 \mathrm{~mm} \times 150 \mathrm{~mm}$ ), for conventional as well as other 
mixes were casted. Each layer was compacted with 25 blow using $16 \mathrm{~mm}$ diameter rod.

\section{A. Compressive Strength Test}

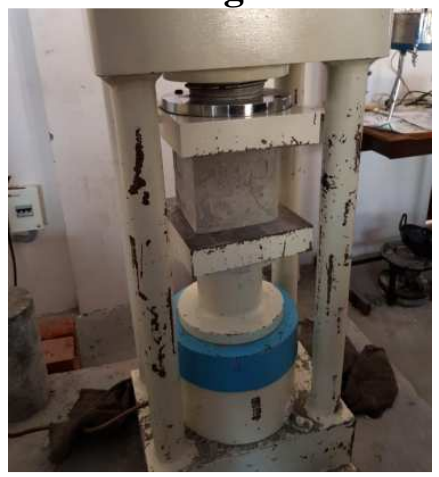

Fig 3 Compression Testing Machine

Compressive test is the most common test conducted on hardened concrete, partly because it is an easy test to perform, the partly because most of the desirable characteristic properties of concrete are qualitatively related to its compressive strength.

The compressive test is carried out on specimens cubical or cylindrical in shape. The cube specimen is of the size $150 \mathrm{~mm} \times 150 \mathrm{~mm} \times 150 \mathrm{~mm}$. The test cube specimens are made as soon as practicable after mixing and such a way as to produce full compaction of the concrete with neither segregation nor excessive laitance.

The concrete is filled into mould in layers approximately $50 \mathrm{~mm}$ deep. The cubes are tested as per IS: 516-1979. The tests are done on an electrohydraulically operated compression-testing machine and compressive load is applied on opposite faces axially, slowly at the rate of $140 \mathrm{MP}$ a/minute. The compressive load is noted for the ultimate failure.

In this project the cement was partially replaced by Titanium oxide in 3\%, $4 \%$ and $5 \%$ by weight of Cement. The Specimens were casted and cured. The Compressive strength of Concrete was determined as per Indian standard Specifications and the results are tabulated under.

Table 4 Comparison of Compressive Strength

\begin{tabular}{|c|c|c|c|c|}
\hline S.NO & \% of $\mathrm{Ti}_{2}$ & $\mathbf{7}$ days & 14 days & 28 days \\
\hline 1 & 3 & 25.04 & 28.88 & 32.6 \\
\hline 2 & 4 & 22.64 & 26.66 & 30.1 \\
\hline 3 & 5 & 19.82 & 21.93 & 27 \\
\hline
\end{tabular}

In this test the concrete containing $\mathrm{TiO} 2$ photo catalysts have been evaluated based on decolourization under sun light, a standard test for self cleaningcementious materials. Experimental data are discussed in relation to dye decolourization of $3 \%$, $4 \%$ and $5 \%$ of $\mathrm{TiO} 2$ replaced concrete under sunlight. On the surface of the casted concrete cubes $1 \mathrm{ml}$ of Rhoda mine dye is dropped on each cube sample and placed under direct sunlight and the results are recorded.

Fig 5 sample cubes placed under sunlight

Fig 6 after 5 hours under sunlight

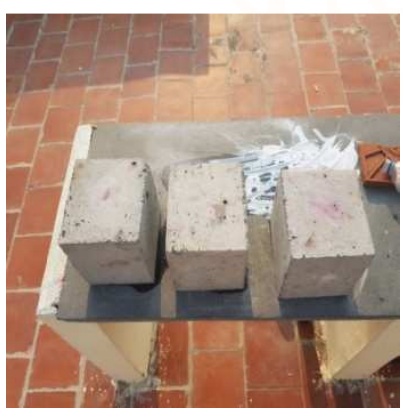

Fig 7After 12 Hours under Sunlight 
The above picture samples show that the decolourization of Rhoda mine dye occurs on the surface of the cubes after some hours. The observation shows that the value of decolourization increases when the percentage of $\mathrm{TiO} 2$ increases.

\section{Nitrogen Dioxide Gas Oxidation Test}

In this experimental test the oxidation time of nitrogen dioxide gas is measured for each sample with $3 \%$, $4 \%, 5 \%$ of titanium dioxide. The time taken by each sample to oxidize the nitrogen dioxide gas is found and the conclusion is made by those results.

PREPARATION OF NO2 GAS

The nitrogen gas is prepared by mixing copper turnings with concentrated nitric acid.

$\mathrm{Cu}+4 \mathrm{HNO} 3=\mathrm{Cu}(\mathrm{NO} 3) 2+2 \mathrm{NO} 2+2 \mathrm{H} 2 \mathrm{O}$

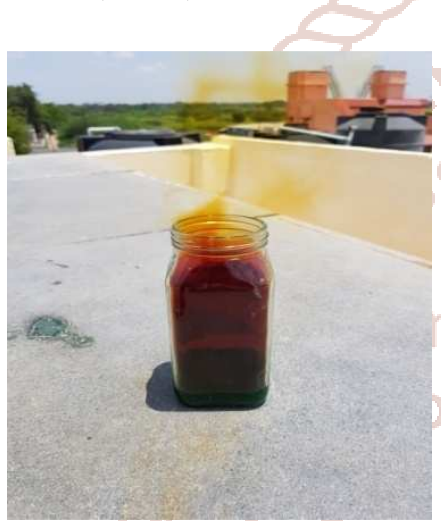

Fig $8 \mathrm{NO}_{2}$ GAS

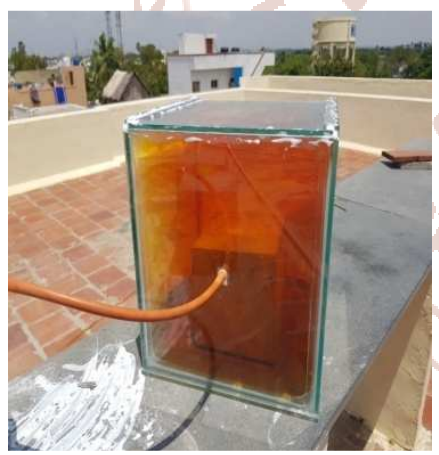

Fig 9 allowing gas to enter into glass cube

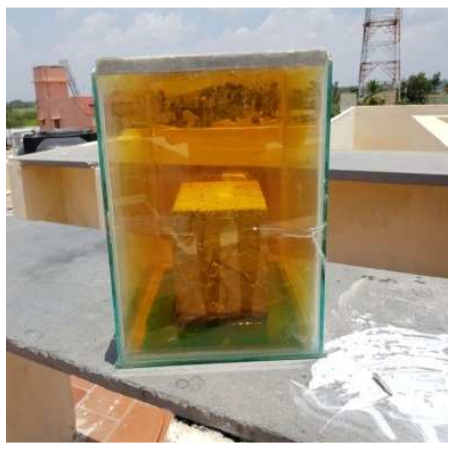

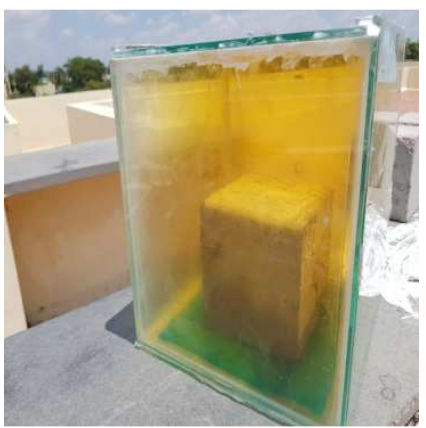

Fig 11 after 2 hours under sunlight

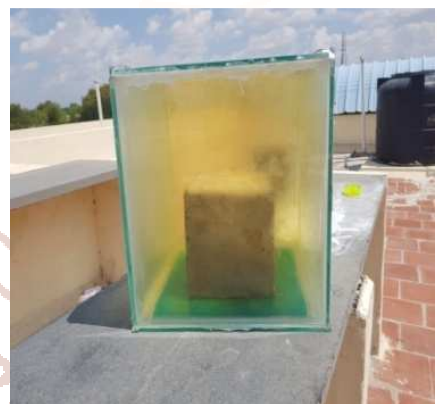

Fig 12 after 3 hours under sunlight

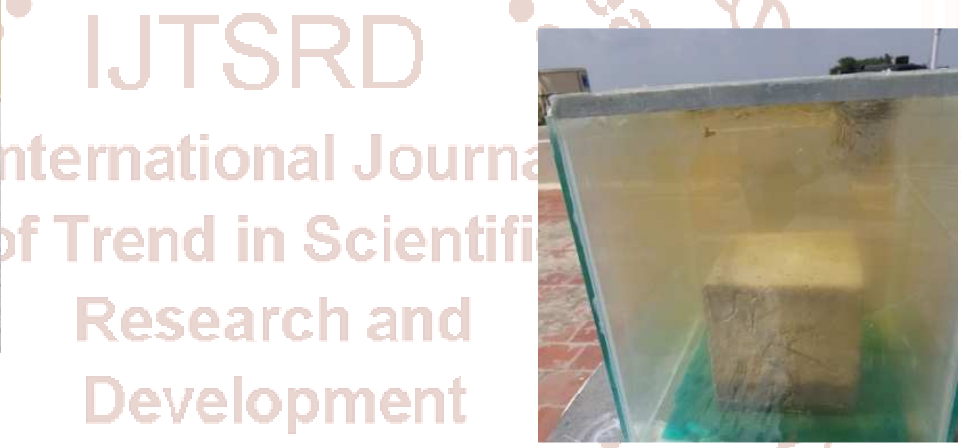

Fig 13 after 4 hours under sunlight
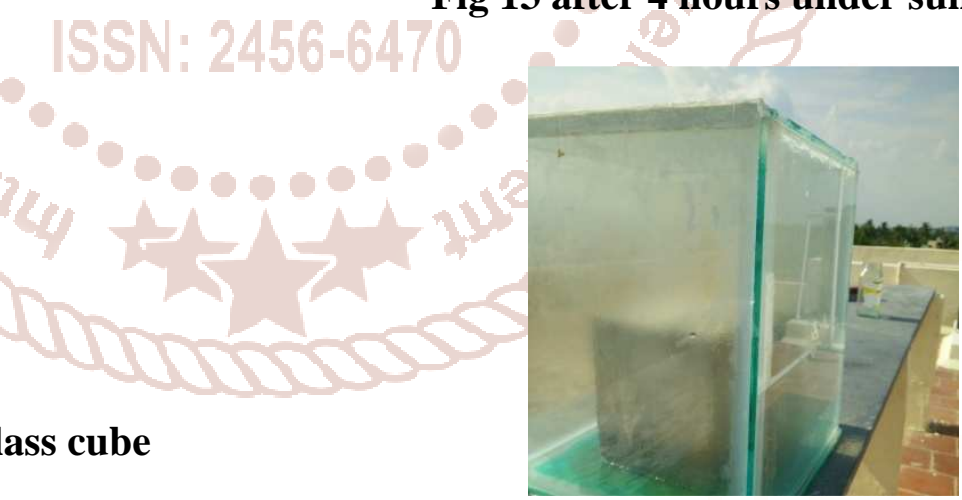

Fig 14 after 5 hours under sunlight

\section{Conclusion}

A. The concrete in which cement is partially replaced by $3 \%$ of titanium dioxide shows gradual increase in compressive strength.

B. Compressive strength of concrete sample with $3 \%, 4 \%$ and $5 \%$ of titanium dioxide after 28 days curing is higher than the target mean strength.

Fig 10 after 1 hour under sunlight 
C. The decolourization test results show that decolourization increases with increase in Titatinium dioxide

D. The oxidation of nitrogen dioxide gas increases with increase in Titatinium dioxide

E. The decolourization and oxidation process is mainly depends on climate of the environment.

F. From above study it is concluded that the use of $3 \%$ of titanium dioxide in concrete sample gives the maximum the strength, decolourization and oxidation increases with increase in Titatinium dioxide
12. Relinque. E. J, J. R. R. Garcia, A. Castillo and M. Castellote, 2015 Cement and Concrete Research, vol. 71, pp. 124-131.

13. Saani. S. H and R. B. Khadiranaikar, 2013 International Journal of Research in Engineering and Technology, pp. 366-371.

\section{References}

1. Aissa. A. H, E. Puzenat, A. Plassais, J. M. Herrman, C. Haehnal and C. Guillard, 2011 Applied Catalysis B : Environmental, vol. 107, pp. 1-8.

2. Banerjee. S, D. D. Doinysiou and S. C. Pillai, 2015 Applied Catalysis B : Environmental, vol. 176, pp. 396-428.

3. Chen. J, S. C. Kou, and C. S. Poon, 2011 Building and Environment, vol. 46, pp. 1827-1833.

4. Chusid. M, 2005 Concrete DECOR, vol.5.

5. Duan. P, C. Yan, W. Luo and W. Zhou, 2016 Construction and Building Materials, vol. 106, pp. 115-125.

6. Feng. D, N. Xie, C. Gong, Z. Leng, H. Xiao, H. Lui and X. Shi, 2013 Industrial and Engineering Chemistry Research, vol. 52, pp. 11575-11582.

7. Janus. M, J. Zatorska, A. Czyzewski, K. Bubacz, E. K. Nejman and A. W. Morawski, 2015 Applied Surface Science, vol. 330, pp. 200-206.

8. Khataee. R, V. Heydari, L. Moradkhannejhad, M. Safar pour and S. W. Joo, 2013 Journal of Nano science and Nanotechnology, vol . 13, pp. 1-6.

9. Khitab. A, M. Alam, H. Riaz, and S. Rauf, 2014 International Journal of Advances in Life Science and Technology, vol. 4, pp. 47-53.

10. Muller. H. S, M. Haist and F. Acosta 2012 Proceedings of the 9th fib International $\mathrm{PhD}$ Symposium in Civil Engineering (Germany, KIT Scientific Publishing).

11. Quagliarini. E, F. Bondioli, G. B. Goff redo and C. Cordoni, 2012 Construction and Building Materials, vol. 37, pp. 51-57. 